\title{
LATEST INVESTIGATIONS ON UNDERPLATFORM DAMPER INNER MECHANICS
}

\author{
(C) 2014 M. M. Gola, C. Gastaldi \\ Politecnico di Torino (Technical University of Torino) Italy
}

\begin{abstract}
Underplatform dampers (UPDs) are widely used as a source of friction damping and are frequently incorporated into compressors and turbines for both aircraft and power-plant applications to mitigate the effects of resonant vibrations on fatigue failure. Due to the nonlinear nature of dry friction, in general dynamic analysis of structures constrained through frictional contacts is difficult, direct time integration with commercial finite element codes may not be a suitable choice given the large computation times. For this reason, ad hoc numerical codes have been developed in the frequency domain. Some authors prefer a separate routine in order to compute contact forces as a function of input displacements, others include the damper in the FE model of the bladed array. All numerical models, however, require knowledge or information of contact -friction parameters, which are established either through direct frictional measurements, done with the help of single contact test arrangements, or by fine tuning the parameters in the numerical model and comparing the experimental response of damped blade against its computed response. The standard approach is to fine-tune and experimentally validate the UPDs models by comparing measured and calculated vibration response of blade pairs. To our knowledge, nobody has ever attempted to directly measure the forces transmitted between the platforms through the damper and the relative damper-platform movement.

In the light of recent results from direct measurements on dampers it is evident that a dedicated routine for the damper mechanics is an effective tool to capture those finer details which are essential to an appropriate description of damper behaviour. This was made possible by the successful effort of the present authors to accurately measure the forces transmitted between the platforms through the damper, to connect them with the relative platforms movement and to use the findings for the validation of the numerical model. The crosscomparison between numerical and experimental results allows to gain a clear understanding of all contact events (stick, slip, lift) which take place during the cycle, and on how they influence the damping performance.
\end{abstract}

Friction damping, underplatform dampers, turbomachines, hysteresis, measurements, numerical model Introduction.

The starting point in the forced response calculation of a mechanical system with friction contacts is the development of the finite element (FE) model of the system (i.e. blade pairs). In order to reduce the calculation time typical of numerical integration of non-linear systems, the harmonic balance method (HBM) can be used to compute the steady-state response of the system [1-3]. In detail, due to the periodicity of the external excitation, also the displacements and the non-linear forces are periodical at steady-state, hence the displacement and friction forces can be approximated by the first terms of their Fourier series.

When dealing with underplatform friction dampers, due to the dual nature of the contact, two different approaches can be found in technical literature. Some authors [4-9], among which Yang and Menq, have developed a separate routine in order to compute contact forces as a function of input displacements. This approach requires the determination of the damper complex contact kinematics and some assumptions such as the approximation of the damper as a rigid body. Others [10-13] have decided to include the damper in the FE model of the bladed array, in order to avoid any assumption about either the damper kinematics or the influence of UPD bulk stiffness on the damper dynamics. Including the damper in the FE element model of the system, however, increases the computational time and does not solve the problem related to the estimation of the contact areas.

In the authors' opinion, the first approach is preferable, since it is more effective in capturing those finer details which are essential to an appropriate description of damper behaviour. Moreover being able to investigate the damper behaviour offline (without involving the FE model of the whole system) considerably shortens any damper optimization process. 
The dedicated routine developed by the AERMEC group combines numerical simulation with a trustworthy experimental approach for these reasons:

- experimental observations can be used as a benchmark to draw the appropriate values of contact parameters (local friction coefficients and contact stiffness) to be used as input to a numerical model which represents the dynamics of the damper between the two platforms (i.e. the dedicated routine). tool.

- validated routine becomes a design

Experimental observations involve:

- a test rig capable of measuring the damper relevant quantities;

- error estimation on the measured and derived quantities to produce trustworthy results;

- results interpretation and estimation of friction contact parameters.

The numerical model requires:

- modeling the damper : the nonconforming contact on the curved damper side is modelled with one contact point, the conforming contact on the flat damper side is modelled with two contact points, whose position is determined according to the wear traces on the damper used in the test rig;

- modeling the test rig, in order to compare the simulated results with the experimental ones;

- identifying a suitable integration scheme and an iteration criteria;

- identifying a suitable contact model to represent the non-linear contact interface behaviour.

Once the validation of the numerical model has been achieved, the simulation of the platforms' behaviour can be removed from the routine. The routine will therefore be able to, given the relative motion of two points (nodes) on the platforms' surface, substitute the non-linear friction forces with their HBM equivalent. In other words the presence of the damper will be substituted with a set of estimated real and imaginary stiffness (as shown in Fig. 1), whose values depend on the platforms' relative motion.

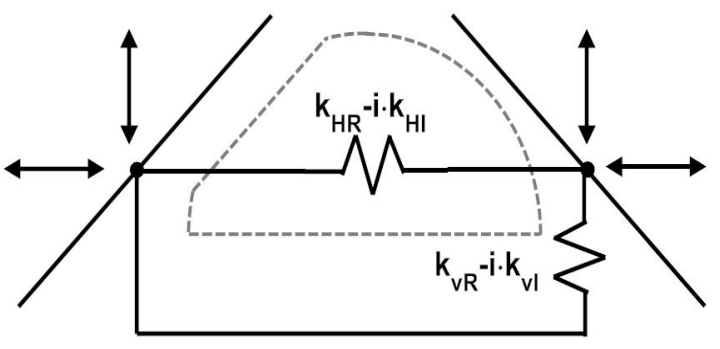

Fig. 1.Damper substitution with a set of complex springs

The results here presented were obtained from a particular type of cylindrical-flat damper, shown in Fig. 1, which is used in practice, slightly adapted to laboratory conditions.

\section{TEST RIG DESCRIPTION}

The test rig, developed over the years by the AERMEC laboratory, focuses its attention on the UPD kinematics and damping capability to the purpose of measuring the relationship between the blade platforms relative displacements and the transmitted contact forces.

In order to achieve this goal the test rig is composed of three main parts:

- a moving part representing the left blade platform, which serves as input motion to the system;

- a fixed part representing the right blade platform, connected, by means of a tripod, to two force sensors which measure the contact forces transmitted between the platforms, through the damper;

- the interposed underplatform damper, held in contact with the platforms by means of a set of wires and pulleys, to reproduce the effect of the centrifugal force.

In-plane periodic displacements are imposed to the left platform by means of two perpendicular piezoelectric actuators; this configuration virtually allows the reproduction of any in-plane trajectory, however in this paper only In-Phase (I-P) and 
Out-of-Phase (O-o-P) motions (see Fig. 2) shall be investigated.

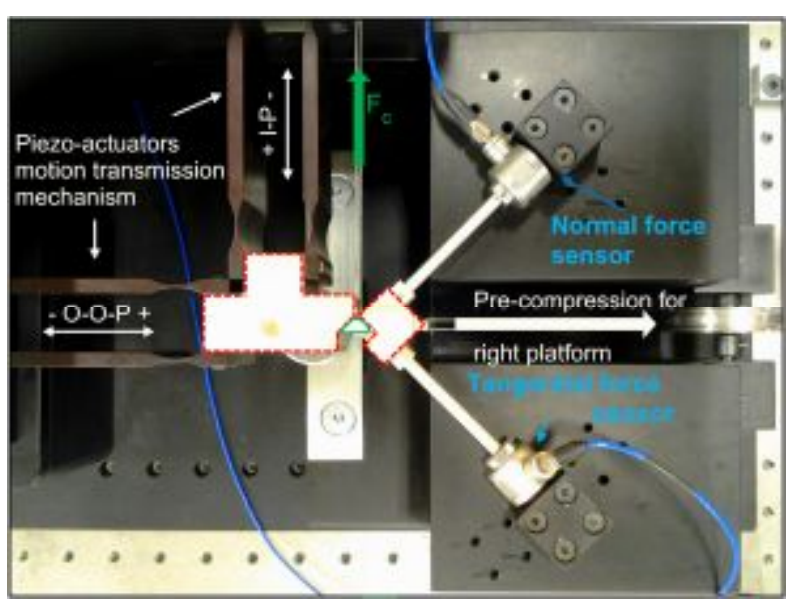

Fig. 2. Overview of the main functional blocks of the test rig. The platforms are red-contoured with dashed lines and the damper is green contoured with solid lines

A deeper understanding of the damper behavior is achieved by investigating its kinematics.

By employing a differential laser vibrometer system with Polytec OFV-3001 controller and OFV-512 sensor head, it is possible to record the damper radial displacement and its rotation angle (the system output kinematical quantities).

Moreover the laser allows to precisely record the input motion (left platform movement relative to the right platform), a necessary precaution because the lack of closed loop control of the piezoelectric actuators, which have a non-negligible compliance, makes displacements dependent on transmitted forces. A complete description of the test rig components and calibration procedures can be found in Gola et. al $[14,15]$.

\section{MEASURED AND DERIVED QUANTITIES}

\section{A. Measured Force Components s}

The readings of the load cells mentioned in the previous section give only the varying components of the right contact force. The zero references of the right contact force components are estimated through a load removal procedure. The procedure simply involves hand lifting the weight acting on the pulling wires pressing the cell and measuring the drop of the signal, as described in [15].

\section{B. Derived Force Components}

Once the complete components of the right contact force $\left(\mathrm{N}_{R}\right.$ and $\left.\mathrm{T}_{\mathrm{R}}\right)$ are known, the damper static equilibrium is reconstructed by neglecting damper inertia (at frequencies where this is correct) and therefore assuming contact and centrifugal forces to pass through one point, as described in [15] and shown in Fig. 3a. In this way $\mathrm{N}_{\mathrm{L}}, \mathrm{T}_{\mathrm{L}}$ and their point of application on the damper are determined.

(b)

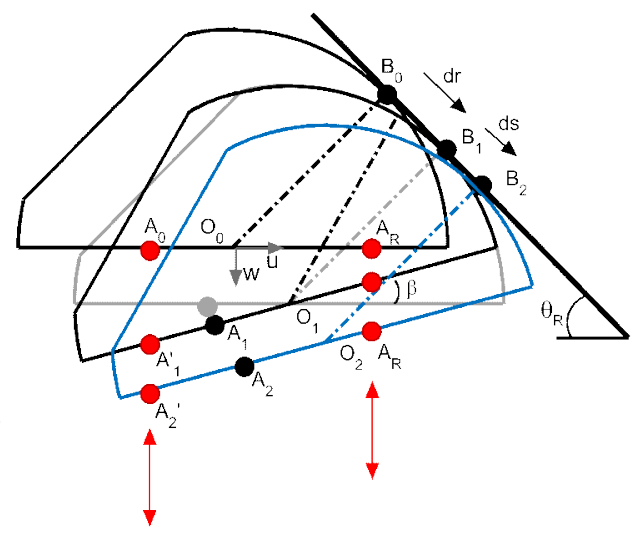

Fig. 3. (a) Damper force equilibrium (b) Damper motion reconstruction 


\section{Measured Kinematic Quantities}

The in-plane kinematics of the damper is reconstructed from measured data:

- the damper rotation $\beta$ is measured by means of a laser differential measurement $\mathrm{w}_{\mathrm{A} 0 \mathrm{AR}}$ between points $A_{0}$ and $A_{R}$ (Fig. 4a);

- damper displacement along radial direction $\mathrm{w}_{\mathrm{A} 0}$. This measurement is obtained by closing the reference eye of the laser, while keeping the beam pointed on $\mathrm{A}_{0}$ open (Fig. 4b); it is subsequently numerically corrected to make it relative to the right platform, whose load is measured and the spring constant is known.

\section{Derived Kinematic Quantities}

The right damper contact point displacement with respect to the right platform is decomposed, with reference to Fig. 3b,

- in a rolling component

$d r \cong \frac{D}{2} \cdot \beta=\frac{D}{2} \cdot \frac{w_{A_{0} A_{R}}}{\overline{A_{0} A_{R}}}$,

- in a purely translational component $d s \cong \frac{w_{A_{0}}+\overline{A_{0} O_{0}} \cdot \sin \beta}{\sin \theta_{R}}-\frac{D}{2} \beta$.

This reconstruction, carefully described in [16] was based on the assumption (justified by the force signal) that the right surface of the damper never loses contact with the right platform. The model used in the kinematic reconstruction presents a simplifying assumption: displacement is computed with respect to physical points (A1 and A2) instead of the ones actually struck by the laser (A'1 and A'2) as shown in Fig. 3b. As was proven in [16], this assumption leads to errors whose magnitude is at least 10 times lower than the uncertainty coming from the measured quantities, therefore the simplified model was used in order to easily perform the analytical error propagation.

\section{MEASUREMENT UNCERTAINTIES}

The experimental results have been assigned, in order to be correctly evaluated and significant, a degree of trust expressed by the uncertainty of the measured and calculated values. In general it holds:

- the force signal has a linearity uncertainty given by the load cells specifications of $1 \%$ of the used range;

- in the case of our load removal procedure, the difference between the measured voltage drop for the given force drop and the one predicted by the calibration factor according to specifications is below $2 \%$;

- the error on the position of the left contact force has been obtained through an error propagation procedure and found to be at $\max 0.6 \mathrm{~mm}$.

- the error on the magnitude of the left contact force has been obtained through an error propagation procedure, typical values are $\sigma_{\mathrm{NL}}=0.7 \mathrm{~N} \sigma_{\mathrm{TL}}=0.9$ (i.e. $3-5 \%$ );

- the uncertainty of laser measured displacement (without further processing) is given by the laser resolution, $0.08 \mu \mathrm{m}$;

- the uncertainty of kinematical quantities related to damper motion which are processed and manipulated through mathematical formulas starting from experimental data $(\beta, d r$ and $d s)$ are obtained through an error propagation procedure i.e. the maximum standard

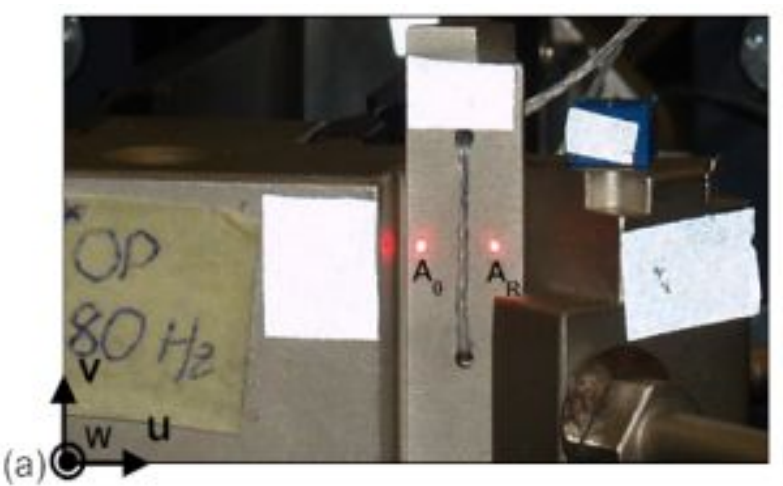

Fig. 4. High quality underexposed pictures taken for the measurement of (a) Damper rotation (b) Damper 
deviation on damper rotation is $0.6 \cdot 10^{-4}$ rad vs. a total damper rotation at $12 \cdot 10^{-4}$ $\mathrm{rad}$, then $5 \%$, in the O-o-P most unfavourable case. This corresponds to a standard deviation of damper-platform relative tangential motion $\left(\sigma_{\mathrm{s}}\right)$ at $\max 0.5$ $\mu \mathrm{m}$ against a total traveled distance of 30 $\mu \mathrm{m}$ in the O-o-P case i.e. again $5 \%$.

\section{A. Recent Improvements on Kinematical Quantities Uncertainty}

Concerning the damper kinematics, an improvement in the estimate of damper rotation and of relative tangential motion at the contact between the damper's cylindrical side and the corresponding platform has recently been obtained thanks to a photographic method.

The main source of uncertainty in the estimation of $d r$ and $d s$ comes from the precision with which the geometrical position of the laser projection points, $\mathrm{A}_{0} \mathrm{O}_{0}$ and $\mathrm{A}_{0} \mathrm{~A}_{\mathrm{R}}$, on the damper surface is known. The uncertainty was minimized by taking a macro, under-exposed (to avoid over-bright laser points) high quality picture (see Fig. 4). The distances are found in pixel coordinates through a graphical software and then converted using the damper diameter as a conversion key. The damper diameter can be easily measured by means of a caliper. Given the high precision of the SW-based measuring tool, the main source of uncertainty comes from the human capacity of estimating the correct measuring position. At high magnification the damper displays blurred edges and the laser dots are not perfectly round (difficulty in locating their center). To take into account these sources of uncertainty a statistical approach is used: for each set of tests, one picture is chosen and 5 independent measurements are carried out. The uncertainty on each quantity is estimated through its standard deviation

\section{NUMERICAL MODEL}

The interpretation of experimental results is quite complex because it requires to relate the behaviour of forces and motions in order to assess the working mode in each part of the hysteresis cycle. A numerical model is then necessary to analyze each tract of the hysteresis cycle by precisely identifying stick or slip conditions and the related exchanged forces.

\section{A. Modelling the Damper and the Test Rig}

The non-conforming contact on the curved damper side is modelled with one contact point, the conforming contact on the flat damper side is modelled with two contact points, whose position is determined by looking at the wear traces on the damper used in the test rig. Stiffness, damping and mass distribution of the test rig are introduced and used to write its dynamic equilibrium equations.

A scheme of the simulated test rig is reported in Fig. 5. The stiffness of structures such as the tripod and the piezoelectric actuators system have been experimentally measured using the procedure described in [15]: compressing a rubber spring between the platforms and thus generating a measurable force, relative displacements have been measured in order to determine all the constants of the spring model. The damping factors of actuator system and tripod mechanisms have all been set equal and a wide range of values $(0-100 \mathrm{~kg} / \mathrm{s})$ has been explored under different working conditions. The influence of the parameter $\mathrm{c}$ was found to be negligible both on the experimental-numerical matching of results and on the numerical stability of the model. Therefore it was decided toset the parameter c to $0 \mathrm{~kg} / \mathrm{s}$.

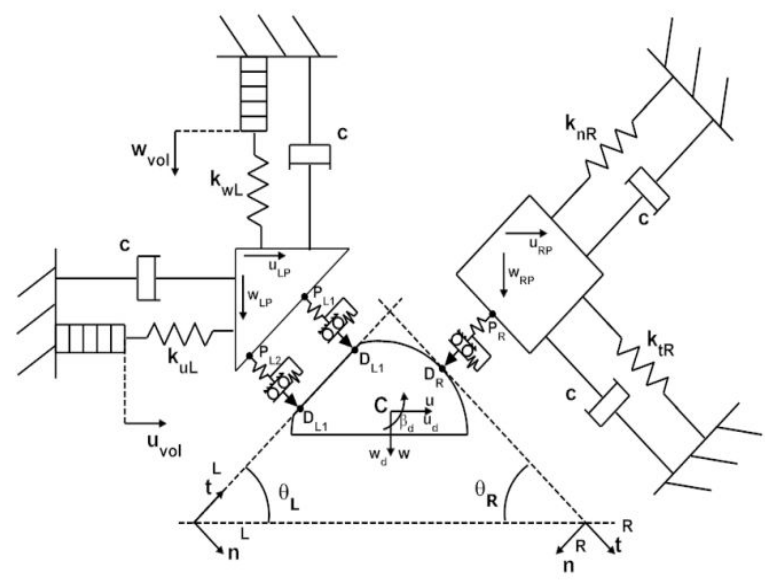

Fig. 5. Numerical model scheme 
A rotational hysteretic damping source, not represented in Fig. 5, is included to account for the presence of the wires connected to the deadweight simulating the centrifugal force.This damping is produced by the bending of the wires together with the contact of the wires when passing through the damper; a precise physical description is considered here not practical, hence the definition of a global rotational damping. It was found through an exploration of experimental data collected at various frequencies ([16]) that the most appropriate assumption was hysteretic damping, and that the best fit value was $\frac{0.1}{f_{c}} \frac{\mathrm{N} \cdot \mathrm{m}}{\mathrm{rad}}$ where $f_{c}$ is the working frequency measured in Hz. This value guarantees a close match of experimental and numerical results for all examined cases.

\section{B. System Equilibrium Equations}

Displacements $\mathrm{u}_{\mathrm{vol}}$ and $\mathrm{w}_{\mathrm{vol}}$ are imposed to the left platform by the piezoelectric actuators. Platform rotations are negligible,thenonly translational motions are taken into account.

The damper has three degrees of freedom including rotation. A general coordinate system (u-w) centered at thedamper mass center is used to write the system equilibrium equations, while two local coordinate systems $\left(t_{L}-n_{L}\right.$ andt $\left.t_{R}-n_{R}\right)$ are used to describe the contact interfaces between damper surface and corresponding platforms. By looking at Fig.6, it is possible to write the system equilibrium equations as follows:

$$
\begin{aligned}
& {[M]\{\ddot{U}\}+[C]\{\dot{U}\}+[K]\{U\}=[B]\left\{F_{c}\right\}+\left\{F_{e}\right\}} \\
& \text { Where } \\
& \{U\}=\left\{u_{d}, w_{d}, \beta_{d}, u_{L P}, w_{L P}, u_{R P}, w_{R P}\right\}^{T}
\end{aligned}
$$$$
\text { is the displacement vector and }
$$$$
\left\{F_{e}\right\}=\left\{0, C F, 0, k_{u L} \cdot u_{v o l}, k_{w L} \cdot w_{v o l}, 0,0\right\}^{T}
$$

is the vector of components of external forces where $\mathrm{CF}$ is the centrifugal force.

$\left\{F_{C}\right\}=\left\{T_{R}, N_{R}, T_{L 1}, N_{L 1}, T_{L 2}, N_{L 2}\right\}^{T}$ is the vector of components of all contact forces and $[B]$ is a geometry matrix necessary to express the contact forces vectors, aligned with the local coordinate systems, in terms of the general one. The mass matrix
$[M]$, damping matrix $[C]$ and stiffness matrix $[K]$ are:

$[M]=\operatorname{diag}\left(m_{d}, m_{d}, I_{d}, m_{L P}, m_{L P}, m_{R P}, m_{R P}\right)$ $[C]=\operatorname{diag}\left(0,0, c_{r d}, c, c, c, c\right)$.

$[K]=\left[\begin{array}{ccccccc}0 & 0 & 0 & 0 & 0 & 0 & 0 \\ 0 & 0 & 0 & 0 & 0 & 0 & 0 \\ 0 & 0 & 0 & 0 & 0 & 0 & 0 \\ 0 & 0 & 0 & k_{u L} & 0 & 0 & 0 \\ 0 & 0 & 0 & 0 & k_{w L} & 0 & 0 \\ 0 & 0 & 0 & 0 & 0 & k_{R 11} & k_{R 12} \\ 0 & 0 & 0 & 0 & 0 & k_{R 21} & k_{R 22}\end{array}\right]$.

Where $\quad k_{R 11}=k_{n R} \cdot \cos ^{2} \theta+k_{t R} \cdot \sin ^{2} \theta$, $k_{R 12}=k_{R 21}=\left(k_{t R}-k_{n R}\right) \cdot \sin \theta \cdot \cos \theta$, $k_{R 22}=k_{n R} \cdot \sin ^{2} \theta+k_{t R} \cdot \cos ^{2} \theta \quad$ with $\theta_{R}=\theta_{L}=\theta$.

The stiffness matrix $[K]$ is not diagonal because of the presence of the springs connected to the right platform oriented along the right local coordinate system's axis. It should be noted that the springs representing contact stiffness, that would couple dampers and platforms equations of motion, do not directly enter the equilibrium equations, but rather they are enclosed in the contact model routine.

\section{Contact Model}

The contact model is used to describe the interface between two non-conforming surfaces. The contact can be simplified as a slider connected with both normal and tangential springs (see Fig. 5). Its input parameters are the relative displacement between surfaces, slider displacement and relevant contact parameters (contact stiffness and friction coefficient). The output variables are the contact forces and the updated slider displacement.

\section{Numerical Solver}

In this work the Newmark method is adopted to numerically solve the system equilibrium equations by assuming the initial state variables. The state variables are interdependent on friction force, therefore an iteration scheme is necessary to find the nonlinear equilibrium point. A displacement based Newton-Raphson iteration scheme was chosen. The complete formulation is reported in [16]. 
V. RESULTS INTERPRETATION AND

ESTIMATION OF FRICTION CONTACT PARAMETERS

The diagrams representing the experimental results together with their numerical match are:

a) Hysteresis Loop (Fig. 6a): i.e. the force transfer between platforms. In the Outof-Phase case here shown the horizontal component of the contact force is plotted as a

(a)

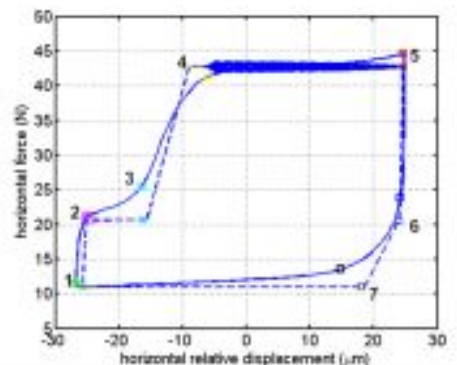

(b)
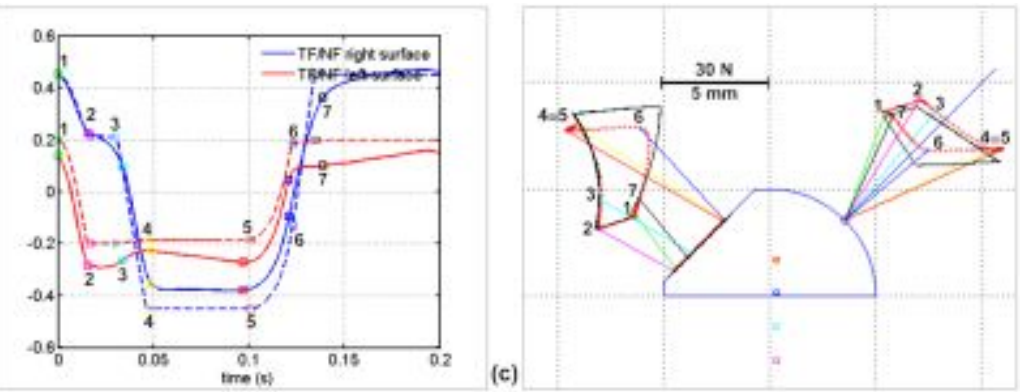

Fig. 6. Experimental (solid lines) and numerical (dashed lines) for (a) O-o-P hysteresis cycle (b) T/N force ratio. (c) Experimental contact forces diagram and (in black) simulated contact forces' trajectories

The force represented in these hysteresis loops is the one obtained after the load-removal process described in Sect. III, i.e., they are the total force values. On the contrary, relativedisplacement between platforms is given directly as measured by the laser, i.e. relative to the mean displacement.

b) $T / N$ force ratios (Fig.6b):it represents the ratio of the total tangential and normal force components on the left and right contact surfaces plotted as a function of time. The flat portions of each line may indicate a slip phase - subject to cross-confirmation by the numerical model - on an interface: in such case the ratio $\mathrm{T} / \mathrm{N}$ will represent a friction coefficient.
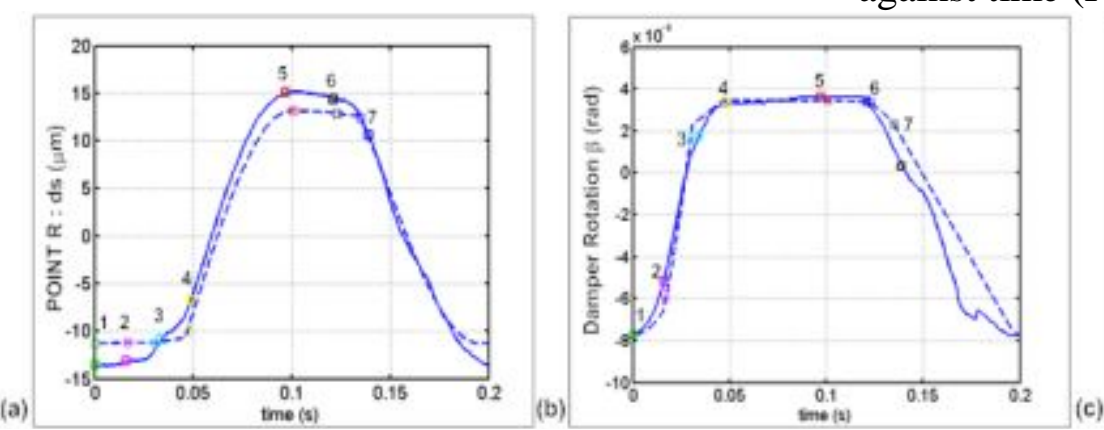

c) Contact forces diagram (Fig. 6c): it represents -) the vectors of forces transmitted between the platforms -) the damper surfaces and -) their points of application. The vectors coming from the measured quantities are calculated as illustrated in Sect. III. The contact forces' trajectories of numerical counterpart are shown, superposed, in black.

d) Kinematic reconstruction (Fig.7): it represents the damper motion reconstructed from experimental data by combining laser measurements $\mathrm{w}_{\mathrm{A} 0}$ and $\mathrm{w}_{\mathrm{A} 0 \mathrm{AR}}$ as described in Sect.III. This operation yields multiple outputs:

- the graph of the tangential translation (ds, no rolling) of the right damper-to-platform contact point, relative to the platform against time (Fig. 7a);

Fig. 7. Experimental (solid lines) and numerical (dashed lines) kinematical reconstruction: (a) Right contact point translational movement with respect to the right platform (b) Damper rotation. (c) Example of reconstructed damper motion during stage 7-1 
- the graph of damper rotation against time (Fig. 7b);

- an example of reconstructed damper motion (Fig. 7c).

\section{A. Estimate of Contact Parameters}

a) Spring stiffness and position: the tangential and normal stiffness at all contact points is here obtained from the experimental evidence.

It has been observed (see [3]) that the slope of the O-o-P hysteresis cycle is equal in all investigated cases and constant in time when the platform starts closing, due to the fact that, in this tract, all contact points are in stick condition, e.g. in the 5-6 O-o-P stage of Fig.6a):

- the position of the resultant left contact force is in the middle of the flat surface, therefore it is assumed that both contact points are in contact (this implies a reduced rotation, Fig. $7 b$ );

- Fig. 6b signals a stick state for both interfaces given the varying Tangential/Normal force ratios;

- the slope used keeps substantially constant throughout the duration of a test (see [3]).

This interpretation of experimental evidence is later confirmed by the numerical simulation.

The cycle slope now under investigation is a composite effect of normal and tangential stiffness values at all contacts. The assumption made here, according to [3], is that all contact points have the same normal and tangential stiffness values. The proportion $\mathrm{k}_{\mathrm{n}}=3 / 2 \mathrm{k}_{\mathrm{t}}$ is initially assumed referring to [14]. The same slope for tract 5-6 can be obtained for any proportion, provided $\mathrm{k}_{\mathrm{n}}$ is given an appropriate value, i.e. it is the linear combination value which counts. However it has been observed that the rotation signal (Fig. 7b) is better approximated by the initial assumption, which is therefore here employed. The contact stiffness values thus obtained are $\mathrm{kn}=84 \mathrm{~N} / \mathrm{mm}$ and $\mathrm{kt}=56 \mathrm{~N} / \mathrm{mm}$ and have been used for the I-P cases as well.

Secondly the position and number of the contact points has to be set. In this case the right side poses no problem since the number and position of the contact points can be determined through the geometry of the damper. The two contact points position on the left surface were instead derived by looking at the wear traces on the damper flat surface: the final position was then finetuned in order to obtain a rotation magnitude as similar as possible to the experimental one. The rotation is particularly sensitive to this parameter, especially in the O-o-P case, given its low magnitude. The final position was set to $0.5 \mathrm{~mm}$ away from the edges for both contact points. This choice was later confirmed by the comparison between the numerical and experimental contact forces distribution diagrams. During the upper left contact point lift-off state, the left contact force is, in the numerical counterpart, coincident with the lower left contact point. The difference between experimental and numerical positions was less than $0.1 \mathrm{~mm}$.

b) Friction Coefficient Values: The friction coefficients can be estimated by looking at the ratio of tangential and normal component of the contact forces in the experimental diagrams (Fig. 6b). The right $\mathrm{T} / \mathrm{N}$ ratio poses no problem since there is only one contact point on that side of the damper. The ratio referring to the left surface is, on the other hand, the result of the combination of the two contact points. When having to estimate the left friction coefficients the following procedure is carried out.

- A stage during which only one of the left contact points is actually in contact and slipping is singled out. The position of the left contact force can be estimated by looking at Fig 6c: when the resultant left contact force is markedly close to one of the edges of the flat surface, the opposite side is probably in lift-off state. In the example hereby presented stages 2-3 was used.

- The ratio TL/NL relative to that stage is used to estimate the lower left contact point friction coefficient $\mu_{\mathrm{L} 2}$.

- Initially $\mu_{\mathrm{L} 1}=\mu_{\mathrm{L} 2}$ is assumed. The result thus obtained is then tuned to match the experimental one.

After the tuning process, the friction coefficients were set, for the case shown in 
Fig.6 and 7 , to $\mu_{R}=0.450, \mu_{L 1}=0.18$, forces, it is numerically convenient to $\mu_{\mathrm{L} 2}=0.199$.

substitute the damper with its HBM equivalent, i.e., with the real and imaginary

\section{B. Complex Springs}

Once the validated numerical model of the damper is able, given the relative motion of two points (nodes) on the platforms' surface, to produce the transmitted platform stiffness of a complex spring.

By way of example Fig. 8 shows diagrams of these complex spring values for the O-o-P case tuned according to data of Fig. 7.

(a)

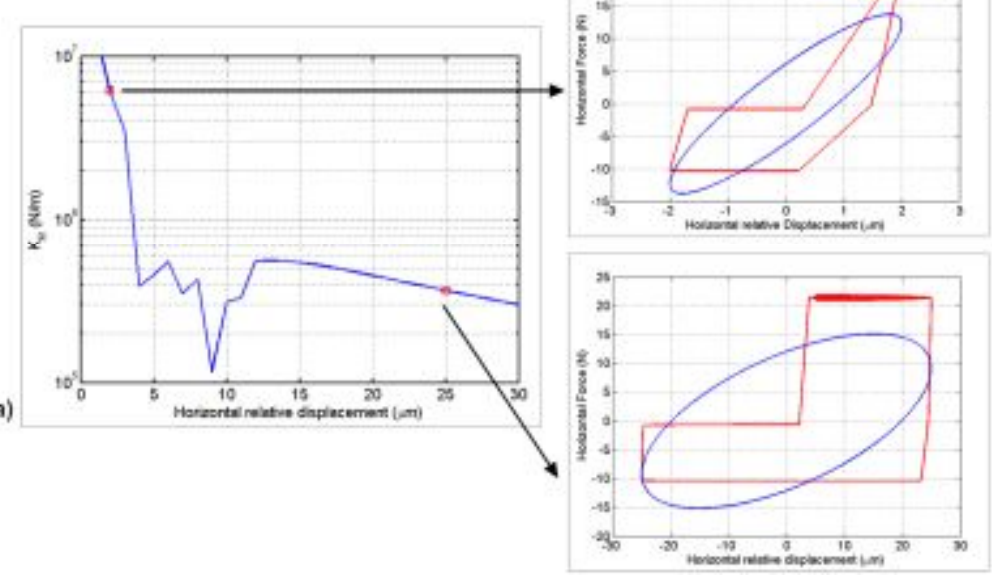

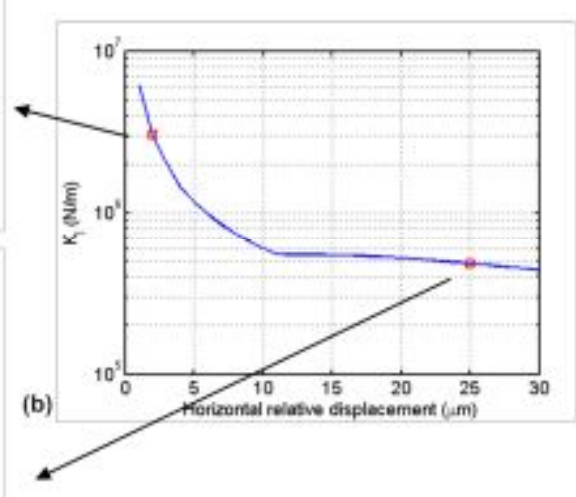

Fig. 8. (a) Real and (b) Imaginary horizontal stiffness values as a function of the relative displacement between platforms. Hysteresis cycles are substituted with ellipses with the same area. Two examples are reported: (above) horizontal relative motion of magnitude $\pm 2 \mu \mathrm{m}$ (below) horizontal relative motion of magnitude $\pm 25 \mu \mathrm{m}$

Finally, it was suggested that accurate hysteresis cycles are the reliable basis to obtain the real and imaginary parts of the complex spring which can be introduced, according to the Harmonic Balance Method, between all the couples of opposite underplatform points in the context of a dynamic FEM model of a blade array.

\section{CONCLUSIONS}

This paper presents a test rig for the direct measurement of damper motion against turbine blade underplatforms and of forces transmitted by the damper. Presents also a numerical dynamic model for the reconstruction of damper motion and damper forces.

The experimental method and the test rig capabilities which allow the measurement of contact forces on one side, and the full reconstruction of all forces transmitted between damper and platforms, have been illustrated. The accuracy of the method was demonstrated for on a cylindrical-flat damper used in practice slightly adapted to laboratory conditions. Results make these authors confident that the reconstruction of damper forces and motion from experimental data is quite reliable and can be safely used for cross-comparison with numerical results.

A trustworthy comparison between numerical and experimental results has a double function. On one side the numerical simulation offers a deeper insight into the damper behaviour in all those details which are not experimentally detectable (e.g. tangential translation ds decomposed in its sliding and spring loading contributions, contact conditions on the flat side of the damper, the fine reasons for the hysteresis cycle shape). On the other side the experimental results allow to fine tune the contact parameters. A sample of results is discussed in order to show, in practice, the procedure to estimate the contact parameters of the numerical model (both tangential and normal contact stiffness and local friction coefficients) starting from the experimental results: the slope of the hysteresis line during a generalized stick state is used to estimate the contact stiffness, while the $\mathrm{T} / \mathrm{N}$ force 
ratios graphs, combined with the contact force distribution diagrams are used to determine the friction coefficients.

It is believed that only an accurate experimental procedure integrated with a numerical prediction tool offers concrete prospects of success when optimizing a damper within the complex set of phenomena highlighted in this paper. At AERMEC we believe that with this approach the optimization of damper mass and geometry will be less a matter of trial and error development and more a matter of knowledge of damper dynamics, allowing to establish design criteria.

Finally, it was suggested that accurate hysteresis cycles are the reliable basis to obtain the real and imaginary parts of the complex spring which can be introduced, according to the Harmonic Balance Method, between all the couples of opposite underplatform points in the context of a dynamic FEM model of a blade array.

\section{References}

1. Cardona A., Lerusse A., Geradin M. Fast Fourier Nonlinear Vibration Analysis // Computational Mechanics. 1998. V. 22, no. 2. P. $128-142$.

2. Griffin J.H. Friction damping of resonant stresses in gas turbine engine airfoils // Journal of Engineering for Power. 1980. V. 102, no. 2. P. 329-333.

3. Petrov E.P., Ewins D.J. Analytical formulation of friction interface elements for analysis of nonlinear multiharmonic vibrations of bladed discs // Transactions of ASME Journal of Turbomachinery. 2003. V. 125, no. 2. P. 364-371.

4. Yang B.D., Menq C.H. Characterization of contact kinematics and application to the design of wedge dampers in turbomachinery blading. Part 1. Stick-slip contact kinematics // Journal of Engineering for Gas Turbines and Power. 1998. V. 120, no. 1. P. 410-417.

5. Yang B.D. Menq C.H., Characterization of contact kinematics and application to the design of wedge dampers in turbomachinery blading. Part 2. Prediction of forced response and experimental verification // Journal of Engineering for Gas Turbines and Power. 1998. V. 120, no. 2. P. 418-423.

6. Csaba G. Modelling of a Microslip Friction Damper Subjected to Translation and Rotation. // Proceeding of ASME Gas Turbine \& Aeroengine Congress and Exhibition. 1999. 99-GT-149.
7. Sanliturk K.Y., Ewins D.J., Stanbridge A.B. Underplatform dampers for turbine blades: theoretical modelling, analysis and comparison with experimental data // Journal of Engineering for Gas Turbines and Power. 1999. V. 123, no. 4. P. 919-929.

8. Panning L., Popp K., Sextro W., Goetting F., Kayser A., Wolter I. Asymmetrical underplatform dampers in gas turbine bladings: theory and application // In Proceedings of ASME Turbo Expo 2004. GT-2004-53316, 2004.

9. Zucca S., Botto D., Gola M.M. Range of variability in the dynamics of semicylindrical friction dampers for turbine blades // In Proceedings of ASME Turbo Expo, GT-2008-51058, 2008.

10. Cigeroglu E., An N., Menq C.H. Forced response prediction of constrained and unconstrained structures coupled through frictional contacts // Journal of Engineering for Gas Turbines and Power. 2009. V. 131, no. 2. Article number 022505.

11. Firrone C.M., Botto D., Gola M.M. Modelling a friction damper: analysis of the experimental data and comparison with numerical results // In: Proceedings of 8th Biennial Conference on Engineering Systems, Design and Analysis (ESDA), 2006.

12. Sanliturk K.Y., Imregun M., Ewins D.J. Harmonic Balance Vibration Analysis of Turbine Blades With Friction Dampers // J. Vib. Acoust. 1997. V. 119, no. 1. P. 96-103. 
13. Sanliturk K.Y., Ewins D.J., 15. Gola M.M., Bragas Dos Santos M., Stanbridge A.B. Underplatform Dampers for Liu T. Measurement of the scatter of Turbine Blades: Theoretical Modeling, underplatform damper hysteresis cycle: Analysis, and Comparison With Experi- experimental approach // In: Proceeding of mental Data // J. Eng. Gas Turbines Power. 1998. V. 123, no. 4. P. 919-929.

14. Gola M.M., Bragas Dos Santos M., Liu T. Design of a new Test Rig to evaluate under-platform damper performance // In proceeding of ESDA 2010. 2010. ASME IDETC 2012. 2012. V. 1, parts A and B. P. 359-369.

16. Liu $\mathrm{T}$. Investigation of underplatform damper kinematics and dynamics. Doctoral dissertation, Politecnico di Torino, Code24268.

2013.

\title{
About the authors
}

Gola Muzio M., Professor of Machine Design, DIMEAS AERMEC Laboratory team leader Politecnico di Torino (Technical University of Torino), Italy. E-mail: muzio.gola@polito.it. Area of Research: Dampers for Turbine Blades: Theoretical Modeling, Analysis.

\section{ПОСЛЕДНИЕ ИССЛЕДОВАНИЯ МЕХАНИЗМОВ С ВНУТРЕННИМИ ПОДПЛАТФОРМЕННЫМИ ДЕМПФЕРАМИ}

\author{
(C) 2014 М. М. Гола, С. Гастальди
}

\section{Туринский политехнический университет (Технический Университет Турина), Италия}

Подплатформенные демпферы (UPDs) широко используются в качестве демпфера трения и часто применяются для уменьшения последствий резонансных колебаний при усталостном разрушении. Они находят применение в компрессорах и турбинах, как в авиационных двигателях, так и в наземных силовых установках. В связи с нелинейной характеристикой сухого трения, обобщённый анализ конструкций, ограниченных трущимися контактами, довольно сложен. Использование конечных элементов с коммерческим кодом не является подходящим выбором в связи с большим объемом времени, требующегося для вычислений. Следствием этого стала разработка специальных цифровых кодов для частных случаев. Некоторые авторы предпочитают использовать отдельную подпрограмму для вычисления контактных сил как функции перемещений (заделок), другие вводят демпферы в конечно элементную модель лопастного венца. Все численные модели, между тем, требуют понимания и знания параметров трения в контакте, которые определяются либо при помощи прямых измерений на трение, выполняемых в ходе испытаний, проводящихся на механизмах с одиночным контактом, либо посредством уточнённой настройки параметров численной модели и сравнения экспериментальных результатов демпфирования лопатки с результатами расчёта. Стандартный подход заключается в точной настройке и экспериментальной проверке UPD моделей путём сравнения измерений и вычисления вибраций в паре лопаток. Насколько нам известно, никто и никогда не пытался непосредственно измерить усилия, передаваемые между поверхностями через демпфер и относительное движение от демпфера до поверхности.

С учётом последних результатов прямых исследований демпферов очевидно, что специализированные подпрограммы для демпфируемых механизмов являются эффективным инструментом для улавливания мелких деталей процесса демпфирования, которые необходимы для соответствующего описания характеристик демпфирования. Это стало возможным благодаря значительным усилиям авторов работы, направленных на точное измерение сил, передаваемых между поверхностями контактов и демпфером. С учётом относительного движения поверхности полученные результаты использовались для проверки численной модели. Перекрестное сравнение расчётных и экспериментальных данных позволяет получить предельно ясное понимание всех случаев контакта 
(спекание, сдвиг, напор), которые проявляются во время цикла работы, а также позволяет оценить степень их влияния на эффективность демпфирования.

Фрикционное демпфирование; подплатформенные демпферы; турбомамины; гистерезис; измерения; представление численной модели.

\section{Информация об авторах}

Гола Музио М., профессор проектирования машин, руководитель группы DIMEAS AERMEC Лаборатория Туринского политехнического университета (технический университет Турина), Италия. E-mail: muzio.gola@polito.it. Область научных интересов: демпферы для турбинных лопаток: теоретическое моделирование, анализ.
Гастальди С., аспирант, DIMEAS Туринский политехнический университет (Технический Университет Турина), Италия. E-mail: chiara.gastaldi@polito.it. Область научных интересов: демпферы для турбинных лопаток: теоретическое моделирование, анализ. 